\title{
Finite Element Modeling of Circular Concrete Filled Steel Tube (CFST)
}

\author{
Tusshar Goel* and Aditya Kumar Tiwary \\ Department of Civil Engineering, Chandigarh University, Mohali - 140413, Punjab, India; g.tusshar7@gmail.com, \\ aditya.civil@cumail.in
}

\begin{abstract}
Background/Objectives: Concrete Filled Steel Tube is an emerging construction technique in India. Due to lack of the data available there is no prescribed design code for the same. Methods/Statistical Analysis: Models were created in order to study the behavior of CFST specimen on ABAQUS V6.14. Its validation is done by comparing its deflected shape and axial load capacity with experimental results. After validation of model a specimen was selected and thickness of steel tube was varied keeping diameter of concrete core constant. Effect on axial load capacity due to friction coefficient between concrete and steel was observed. Findings: It was found that plastic hardening using plastic hardening equations gave best results for the confined concrete composite and friction coefficient between concrete and steel tube has no significant effect on axial load capacity. Local buckling was the most common failure in short CFST however in case of long columns buckling failure is also noticed. Axial load capacity of specimen changes linearly with steel tube thickness keeping diameter of concrete core constant. Improvements/Applications: The stresses in individual components of composite at various stages of loading was found which helps in understanding of composite and in creation of design code for the same.
\end{abstract}

Keywords: Analytical Analysis, Composite, Concrete Filled Steel Tube Columns, Finite Element Method

\section{Introduction}

Due to the less availability of land, there is need of structures that can support a large number of people for various activities. This in turn demands for high performance by structural members. High Strength Concrete (HSC) are very useful for decreasing the size of concrete members but they are very brittle $\stackrel{1}{ }$. As the strength of concrete increases its ductility decreases. In previous studies, researchers have found that the ductility could be improved by confining concrete. Now active confinement and passive confinement are the two methods for providing confinement to concrete ${ }^{2}$. One of the methods to provide active confinement is by lateral pre-stressing. Main advantage of actively confined concrete is that confinement is effective even before the formation of splitting cracks. Due to these reasons it can be said that active confinement is much more efficient than that of passive confinement and is preferable in large projects. On the other hand, passive confinement can be introduced by restraining the lateral strain in concrete. This is further done by providing transverse ties (conventional way) in the specimen but there are limitations to it.

Firstly, the spacing of transverse reinforcement needs to be kept very less for effective confinement of concrete. On the other hand, if we keep the transverse reinforcement quite closely spaced it results in congestion while concreting ${ }^{3}$. Secondly, the confining effect is introduced in the concrete through the arching action by the bends in the transverse reinforcement. The confining stress reduces with increasing distance from the bend ${ }^{ \pm}$. Other method of providing passive confinement is to confine the concrete in confining material (like steel tube, fiber reinforced polymer etc).

In previous studies it was found that Concrete Filled Steel Tube (CFST) performs better than conventional RCC construction. In this system (CFST), by confining the concrete core, steel tube act as the transverse reinforce-

${ }^{*}$ Author for correspondence 
ment and longitudinal reinforcement both at the same time. Steel tube in the CFST also acts as the permanent formwork and omission of reinforcing bars decreases the construction time and cost $\frac{4-7}{}$. The confining of concrete core provided by steel tube delays the micro cracks formation and reduces the splitting crack width ${ }^{\circ}$.

Due to difference in the Poisson's ratio of concrete and steel ( 0.18 and 0.3 respectively) at the initial elastic stage the lateral strain in concrete is lesser than that of steel tube and the hoop stress in steel tube is quite small. The hoop stress in steel tube becomes noticeable when dilatency of concrete is larger than before and becomes inelastic ${ }^{9}$. Furthermore, this difference in Poisson's ratio and stresses, delamination of concrete from steel becomes a permanent problem which decreases the effectiveness of confinement of concrete ${ }^{10}$.

As the concrete is brittle in nature, it has more compressive strength than tensile strength whereas steel being ductile in nature is strong in tension. When we apply tensile stresses on CFST composite of these two materials, steel has the ability to show more strain than concrete. To study the effect of debonding on circular CFST stub columns a research was conducted and it was found that the phenomenon of local buckling in circular steel tube in debonded specimen is much more severe than that of specimen without debonding $\underline{\underline{11}}$. Bond behavior between concrete and steel in Concrete Filled Steel Tube was also studied by performing a number of push-out tests on circular CFST specimens. It was concluded that the bond strength between steel tube and concrete core could be improved by providing the welded steel rings onto the internal surface of steel tube. Expansive concrete and welded shear studs onto the inside surface of steel tube have also been proven to be good methods to improve the bond strength after welding internal steel rings ${ }^{12}$.

Steel tube in CFST provides only passive confinement to the concrete by retraining the lateral strain. The confining stress produced depends upon the lateral strain in the specimen and lateral strain in turn depends on the confining stress. This makes it difficult to calculate the inter-related lateral strain and the confining stress. For simplifying calculations stresses are assumed to be uniform in the specimen along the two minor principal axes of the cross-section $\frac{13,14}{}$. This assumption is theoretical and holds good in case of circular steel tube under axial load without eccentricity. But in case of CFST specimens with square and rectangular cross section have non-uniform confining stress due to the arching action at the corners like in case of stirrups in conventional RCC system and buckling effect at the centre of edges. CFST specimens having eccentric load also show non-uniform confining stresses in the specimen. In a study performed on performance of centrally loaded CFST with different shapes it was concluded that circular CFST have more ultimate strength than square CFST. However, in other study it was found that square CFST columns perform better than circular CFST in terms of lateral displacement $\frac{15}{}$.

\section{Materials and Methods}

\subsection{Steel}

The idealized stress-strain curve for steel is shown in Figure 1. For simplicity, stress-strain curve of steel is idealized as trilinear curve. The curve is divided into three parts with three linear curves. First part of the curve is elastic in nature upto the yield point with slope equal to the elastic modulus of steel (usually $210 \mathrm{GPa}$ ). The second part is constant at yield stress $\mathrm{f}_{\mathrm{y}}$ which is plastic in nature. The third part of the curve shows the strain hardening $\varepsilon_{t}$ in steel ending upto ultimate stress $\mathrm{f}_{\text {ult }}$ and ultimate strain $\varepsilon_{\mathrm{u}}$ of steel. The ultimate strain in the steel tube of specimen $\varepsilon_{\mathrm{u}}$ is assumed to be $0.2^{\frac{16}{}}$. The Poisson's ratio of steel tube is assumed to be 0.3 .

$$
\varepsilon_{t}=10 \varepsilon_{y}
$$

The stress curve of steel imagined as tri-linear curve

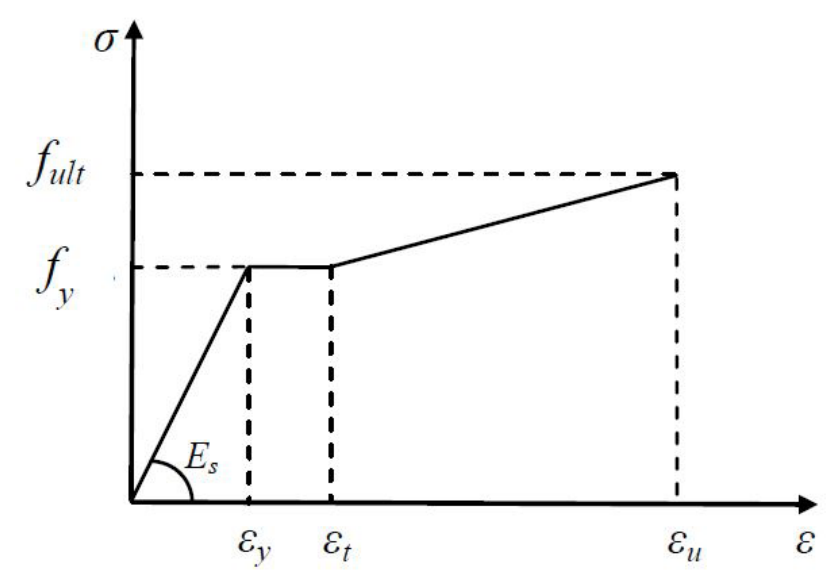

Figure 1. Idealized trilinear stress-strain curve for steel. 


\subsection{Concrete}

Stress strain curve for confined concrete compared with unconfined concrete is shown in Figure $2^{\frac{17}{}}$.

The stress strain relation diagram of concrete is also divided into three parts. First part of the curve is linear upto stress $\left(0.5 \mathrm{f}_{\mathrm{cc}}\right)$ with young's modulus $\mathrm{E}_{\mathrm{c}}$ calculated by using formula according to ACI (1999).

$$
E_{c}=4700 \sqrt{f_{c c}}
$$

Where $f_{c c}$ is confined concrete compressive strength calculated by using relations given below $\underline{18}$.

$$
\begin{aligned}
& f_{c c}=f_{c}+k_{1} f_{1} \\
& \varepsilon_{c c}=\varepsilon_{c}^{\prime}\left(1+K_{2} \frac{f_{1}}{f_{2}}\right)
\end{aligned}
$$

$\mathrm{f}_{\mathrm{cc}}=$ compressive strength of concrete in confined state.

$\mathrm{fc}=$ compressive strength of concrete in unconfined state.

$\varepsilon_{\mathrm{cc}}=$ strain in confined concrete.

$\varepsilon_{\mathrm{c}}^{\prime}=$ strain in unconfined concrete

$\mathrm{k}_{1}$ and $\mathrm{k}_{2}$ are constants and can be assumed as 4.1 and 20.5 respectively ${ }^{19}$. The value of $f_{1}$ for circular CFST can be evaluated using empirical equations.

$$
\begin{array}{ll}
\frac{f_{1}}{f_{y}}=0.043646-0.000832\left(\frac{D}{t}\right) & \text { for } 21.7 \leq \frac{\mathrm{D}}{\mathrm{t}} \leq 47 \\
\frac{f_{1}}{f_{y}}=0.006241-0.0000357\left(\frac{D}{t}\right) & \text { for } 47 \leq \frac{\mathrm{D}}{\mathrm{t}} \leq 150
\end{array}
$$

Where,

$\mathrm{f}_{\mathrm{v}}=$ yield strength of the steel tube.

$\mathrm{D}=$ diameter of the CFST specimen.

$\mathrm{t}=$ thickness of the steel tube.

The second part of curve for confined concrete can be expressed by following Equations ${ }^{\underline{20}}$ :

$$
f=\frac{E_{c} \varepsilon_{c}}{1+\left(R+R_{E}-2\right)\left(\frac{\varepsilon_{c}}{\varepsilon_{c c}}\right)-(2 R-1)\left(\frac{\varepsilon_{c}}{\varepsilon_{c c}}\right)^{2}+R\left(\frac{\varepsilon_{c}}{\varepsilon_{c c}}\right)^{3}}
$$

$$
\begin{aligned}
& R_{E}=\frac{E_{C} \varepsilon_{C C}}{f_{c c}} \\
& R=\frac{R_{E}\left(R_{\sigma}-1\right)}{\left(R_{\varepsilon}-1\right)^{2}}-\frac{1}{R_{\varepsilon}}
\end{aligned}
$$

$\mathrm{R}_{\varepsilon}$ and $\mathrm{R}_{\sigma}$ are constants and can be assumed as 4.0. The last part of the curve is assumed to be linear upto the ultimate strength and ultimate strain of confined concrete.

$$
\begin{aligned}
& f_{u}=K_{3} f_{c c} \\
& \varepsilon_{u}=11 \varepsilon_{c c}
\end{aligned}
$$

The value of $\mathrm{K}_{3}$ for circular Concrete Filled Steel Tube can be calculated as:

$$
\begin{gathered}
K_{3}=1 \text { for } 21.7 \leq \frac{\mathrm{D}}{\mathrm{t}} \leq 40 \\
K_{3}=0.000039\left(\frac{D}{t}\right)^{2}-0.010085\left(\frac{D}{t}\right)+1.3491 \text { for } 40 \leq \frac{\mathrm{D}}{\mathrm{t}} \\
\leq 150
\end{gathered}
$$

By default, in ABAQUS using "Penalty" method, frictional constraints are enforced with a stiffness having a finite value. In case the sticking stiffness is infinite the elastic slip will be zero.

The relation between traction shear stress versus elastic slip is shown in Figure 3.

Where,

$\tau_{\text {crit }}=$ yield stress.

$k=$ young's modulus.

\section{Comparison of stress strain curve between unconfined and confined concrete}

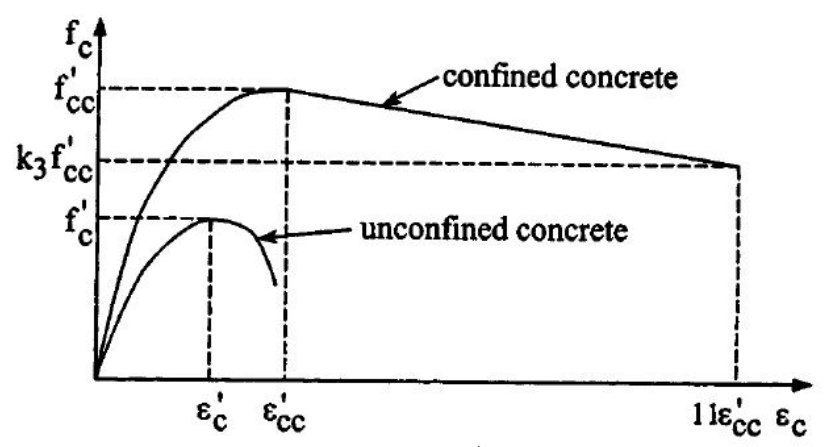

Figure 2. Stress strain curve of unconfined and confined concrete. 


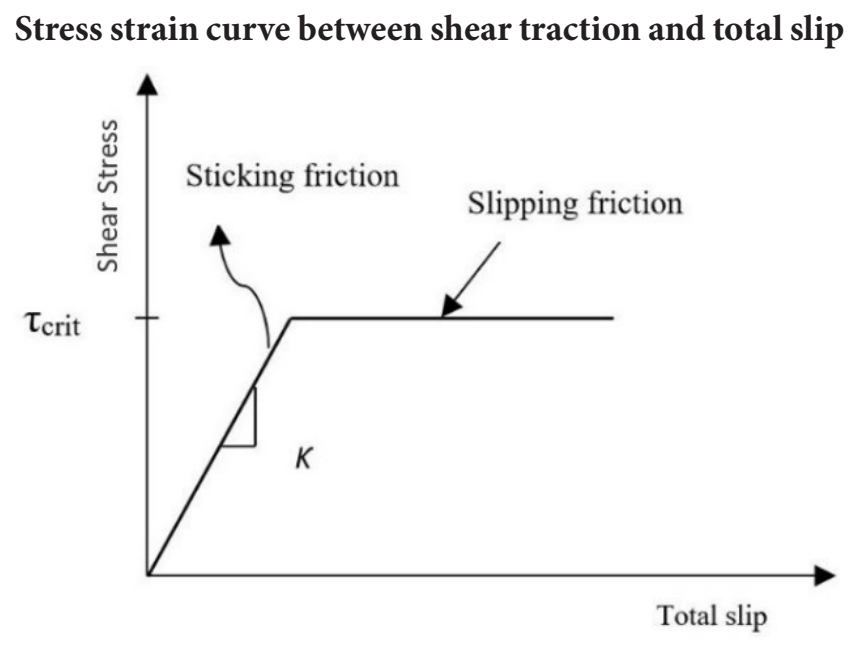

Figure 3. Shear traction versus elastic slip relationship for sticking and slipping friction.

\subsection{Linear Drucker Prager Rule (Plastic Flow)}

Flow potential versus equivalent stress adopted in Linear Drucker Prager rule is shown in Figure 4.

$\mathrm{G}$ is the flow potential and can be written as:

$$
G=t-p \tan \psi
$$

Where,

$p=$ equivalent stress

$G=$ flow potential

$\varphi=$ dilation angle

and

$$
t=\frac{1}{2} q\left\{1+\frac{1}{K}-\left(1-\frac{1}{K}\right)\left(\frac{r}{q}\right)^{3}\right]
$$

Non-associated flow is usually preferred with linear model for granular materials, in the sense that the flow is assumed to be normal to the yield surface but with an angle $\psi$ to the t-axis $(\psi<\varepsilon)$. The original Drucker Prager model has associated flow with settings $\psi=\varepsilon$ and $K=1 . \varphi=0$ represents that the inelastic deformation is incompressible. $\Psi \geq 0$ means that the material can dilate. Here $\varphi$ is the dilation angle and $\varepsilon$ is the friction angle. Stress strain linear curve between flow potential and
equivalent stress.

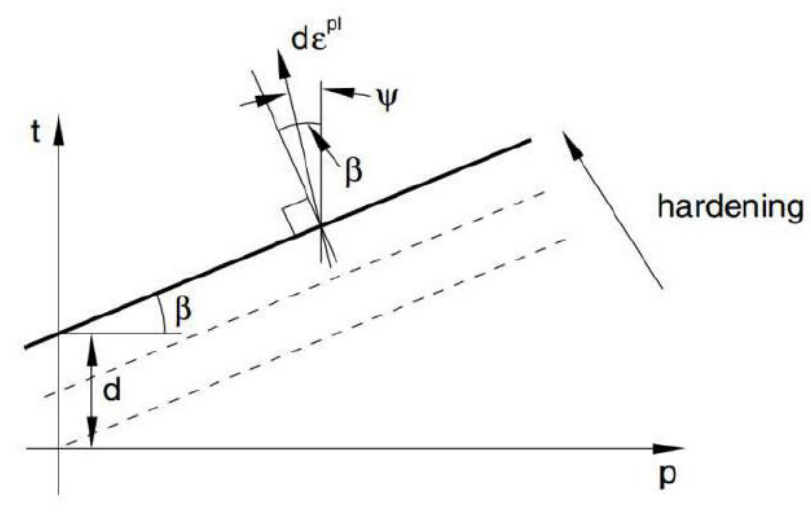

Figure 4. Linear drucker prager model.

\section{FE modelling of CFST specimens:}

In this study circular Concrete Filled Steel Tube is modeled on commercially available software ABAQUS 6.14. CFST was modeled with two rigid plates at top and bottom with their respective reference nodes. A point load was exerted at reference node of the top plate. The bottom plate was kept fixed in all directions and top plate was restrained in all directions except in the longitudinal direction of specimen.

For solid elements ABAQUS 6.14 provides a set of standard elements. Most commonly used elements for modeling are (C3D4) 4-node linear tetrahedron, (C3D6) 6-node linear triangular prism, (C3D8) 8-node linear brick element. Each individual node of these elements has 3 translational degrees of freedom (DOF's). Two of these elements (C3D4 and C3D6) doesn't convergence properly and require fine mesh. But these fine meshes require a lot of computational time. Therefore, C3D8 element is preferred over C3D4 and C3D6 for solid continuum body. A single layer of C3D8R element was used along the thickness of the steel tube instead of shell elements to provide proper curved contact boundary between concrete core and steel tube ${ }^{21}$. For concrete core also C3D8R element was used and for rigid plates R3D4 element. The size of the mesh was kept $20 \mathrm{~mm}$ due to time constraint. According to the literature available finer mesh provide very accurate results but coarse mesh of $20 \mathrm{~mm}$ size provides acceptable results. 
Tie constraints were created between each plate with top and bottom nodes of both steel and concrete. For interaction, surface to surface contact was created between steel tube and concrete core with tangential behavior. Penalty method (also known as stiffness method) is used for imposing frictional constraints. This stiffness method allows the relative motion between the surfaces of two materials even when they are sticking. The magnitude of slip is limited to elastic slip while they are sticking $(\tau \leq$ $\tau_{\text {crit }}$.) Under "Penalty" various values of friction coefficient, stiffness and shear stress limit were used with isotropic directionality.

While defining the plastic properties of concrete in some models, linear Drucker Prager rule was used since the compressive stresses dominate in axially loaded CFST. Associated plastic flow was considered which implies dilation angle equal to friction angle. The value of flow stress ratio is between 0.778 and 1.0 (ABAQUS 6.14 Documentation). So, the values of friction angle, dilation angle and stress flow ratio were assumed as $20^{\circ}, 20^{\circ}$ and 0.8 respectively. However, in other models plastic hardening was used instead of Drucker Prager hardening and equations given in section 2.2 were used to find absolute plastic strain with corresponding shear stress.

After validating the model, a specimen was selected whose strength is varied by changing steel tube thickness and keeping diameter of concrete core constant. As shown in Figure 5 the strength vs. steel tube thickness is linear if the diameter of concrete core is kept constant.

Comparison between simulated and experimental deflected shape of CE specimen used for validation

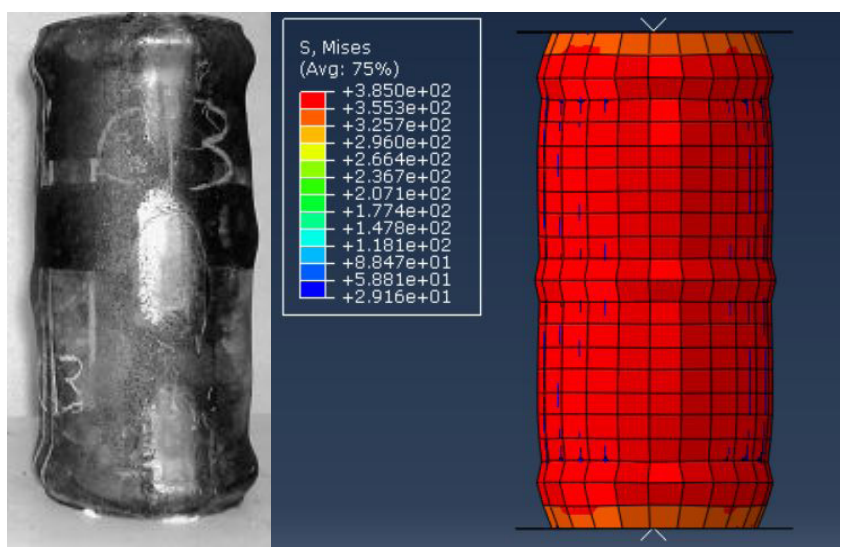

Figure 5. Deflected shape C3 specimen [23] and Deflected shape and average stresses in simulated model.

\subsection{Effect of Friction on Axial Load Capacity}

Specimen $\mathrm{C} 12$ was modeled with different friction coefficients between concrete and steel interface. Friction coefficient was varied from 0.05 to 0.5 keeping all other parameters of the model constant. In normal RCC type construction the transfer of load between concrete and reinforcement is through friction and bond stress. However, in case of CFST where the internal surface of steel tube is smooth, the transfer of load between steel tube and concrete is through lateral strain and confining stress. This internal friction and bond stress can be improved by welding internal rings on the inside surface of steel tube.

\section{Results and Discussion}

Simulated axial load capacity is compared with experimental axial load capacity of different specimens with their dimensions, properties and references is shown in Table $1 \frac{22,23}{}$.

Simulated deflected shape of C3 specimen compared with experimental deflected shape used for validation. Load vs. displacement graph of $\mathrm{C} 12$ specimen obtained from ABAQUS V6.14 is shown in Figure 6.

Load vs. displacement graph of $\mathrm{C} 1$ specimen obtained from ABAQUS V6.14 is shown in Figure 7.

Load vs. displacement graph of CC4-A-2 specimen obtained from ABAQUS V6.14 is shown in Figure 8.

Axial load capacity at different steel tube thickness is shown in Table 2.

Variation of axial load capacity with steel tube thickness for CC4-A-2 specimen is shown in Figure 9.

Axial load capacity at different friction coefficient between steel tube and concrete core is shown in Table 3.

Stresses in cut section of steel tube and concrete core at $75 \%$ load stage is shown in Figure 10. 


\section{Comparison of axial load capacities between simulated and experimental for various specimens}

Table 1. Simulation and experimental results of the specimens with material properties

\begin{tabular}{|l|c|c|c|c|c|c|c|c|c|c|}
\hline Specimen & $\mathrm{D}(\mathrm{mm})$ & $\mathrm{t}(\mathrm{mm})$ & $\mathrm{L}(\mathrm{mm})$ & $\mathrm{Ec}(\mathrm{MPa})$ & $\mathrm{Es}(\mathrm{MPa})$ & fy $(\mathrm{MPa})$ & $\mathrm{fc}(\mathrm{MPa})$ & Pexp $(\mathrm{KN})$ & Psim(KN) & Reference \\
\hline C1 & 140.8 & 3 & 602 & 25599 & 189475 & 285 & 28.18 & 881 & 838 & {$[22]$} \\
\hline C2 & 141.4 & 6.5 & 602 & 23528 & 206011 & 313 & 23.8 & 1825 & 1700 & {$[22]$} \\
\hline C3 & 140 & 6.68 & 602 & 28180 & 205322 & 537 & 28.18 & 2715 & 2520 & {$[22]$} \\
\hline CC4-A-2 & 149 & 2.96 & 447 & N/A & N/A & 308 & 25.4 & 941 & 904 & {$[4]$} \\
\hline CC4-A-4-1 & 149 & 2.96 & 447 & N/A & N/A & 308 & 40.5 & 1064 & 1077 & {$[6]$} \\
\hline CC4-C-2 & 301 & 2.96 & 903 & N/A & N/A & 279 & 25.4 & 2382 & 2362 & {$[6]$} \\
\hline CC4-D-2 & 450 & 2.96 & 1350 & N/A & N/A & 279 & 25.4 & 4415 & 4250 & {$[6]$} \\
\hline CC6-A-2 & 122 & 4.54 & 366 & N/A & N/A & 576 & 25.4 & 1509 & 1455 & {$[6]$} \\
\hline CC6-D-2 & 361 & 4.54 & 1083 & N/A & N/A & 525 & 25.4 & 5633 & 5505 & {$[6]$} \\
\hline C3 & 114.4 & 3.98 & 300 & N/A & N/A & 343 & 31.4 & 948 & 1010 & {$[23]$} \\
\hline C12 & 114.3 & 3.85 & 300 & N/A & N/A & 343 & 31.9 & 998 & 981.25 & {$[23]$} \\
\hline C13 & 114.09 & 3.85 & 300.5 & N/A & N/A & 343 & 31.9 & 948 & 905 & {$[23]$} \\
\hline
\end{tabular}

${ }^{*}$ Ultimate strength of steel is assumed to be $1.25 \mathrm{f}_{\mathrm{y}}$

Where,

$\mathrm{D}=$ diameter of the specimen.

$\mathrm{L}=$ length of steel tube.

$\mathrm{t}=$ thickness of steel tube.

$\mathrm{f}_{\mathrm{c}}=$ compressive strength of concrete in unconfined state.

$\mathrm{f}_{\mathrm{y}}=$ yield strength of steel tube.

$\mathrm{E}_{\mathrm{s}}=$ Elastic modulus of steel.

$\mathrm{P}_{\exp }=$ Experimental ultimate load capacity.

$\mathrm{P}_{\text {sim }}=$ Simulated ultimate load capacity.

$\mathrm{E}_{\mathrm{c}}=$ Elastic modulus of unconfined concrete.

\section{Axial load capacity of samples varying with steel tube thickness}

Table 2. Strength with changing steel tube thickness CC4-A-2 specimen

\begin{tabular}{|l|c|c|}
\hline \multicolumn{1}{|c|}{ S. No } & Thickness $(\mathbf{m m})$ & $\mathbf{P}_{\text {sim }}(\mathbf{K N})$ \\
\hline 1 & 3.0 & 904 \\
\hline 2 & 3.5 & 1063 \\
\hline 3 & 4.0 & 1218 \\
\hline 4 & 4.5 & 1357 \\
\hline 5 & 5.0 & 1482 \\
\hline 6 & 5.5 & 1620 \\
\hline
\end{tabular}

\section{Axial load capacity of samples varying with friction coefficient between concrete and steel tube}

Table 3. Axial capacity at different friction coefficient between concrete and steel interface of $\mathrm{C} 12$ specimen

\begin{tabular}{|c|c|c|}
\hline S. No. & Friction Coefficient & $\mathbf{P}_{\text {sim }}(\mathbf{K N})$ \\
\hline 1 & 0.05 & 981.25 \\
\hline 2 & 0.10 & 981.25 \\
\hline 3 & 0.15 & 981.30 \\
\hline 4 & 0.20 & 981.30 \\
\hline 5 & 0.25 & 981.35 \\
\hline 6 & 0.30 & 981.35 \\
\hline 7 & 0.40 & 981.35 \\
\hline 8 & 0.50 & 981.35 \\
\hline
\end{tabular}


Load vs. displacement graph obtained as field output for C12 specimen on ABAQUS V6.14

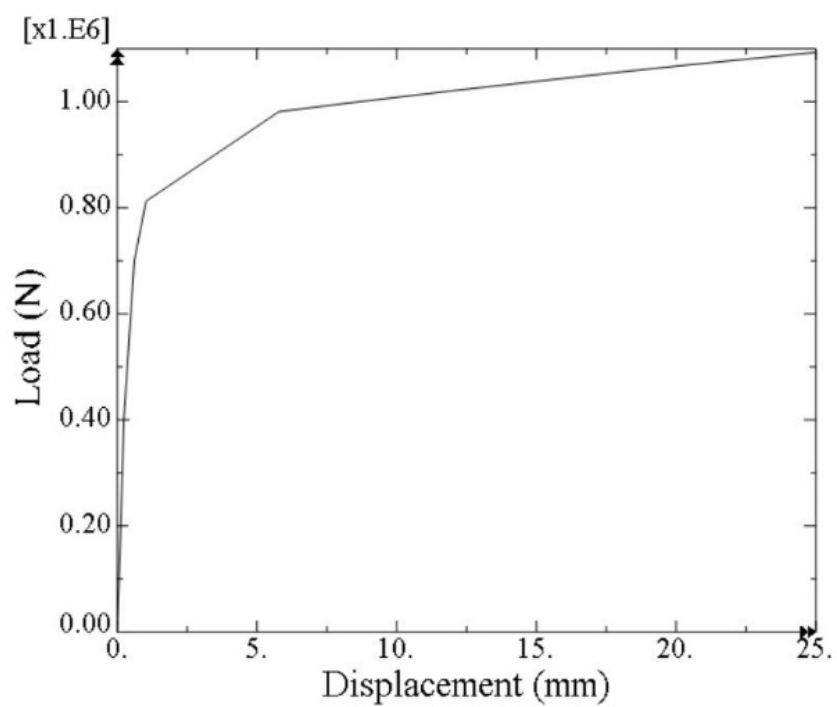

Figure 6. Load vs. displacement graph of $\mathrm{C} 12$ specimen in ABAQUS v6.14.

\section{Load vs. displacement graph obtained as field output for $\mathrm{C} 1$ specimen on ABAQUS V6.14}

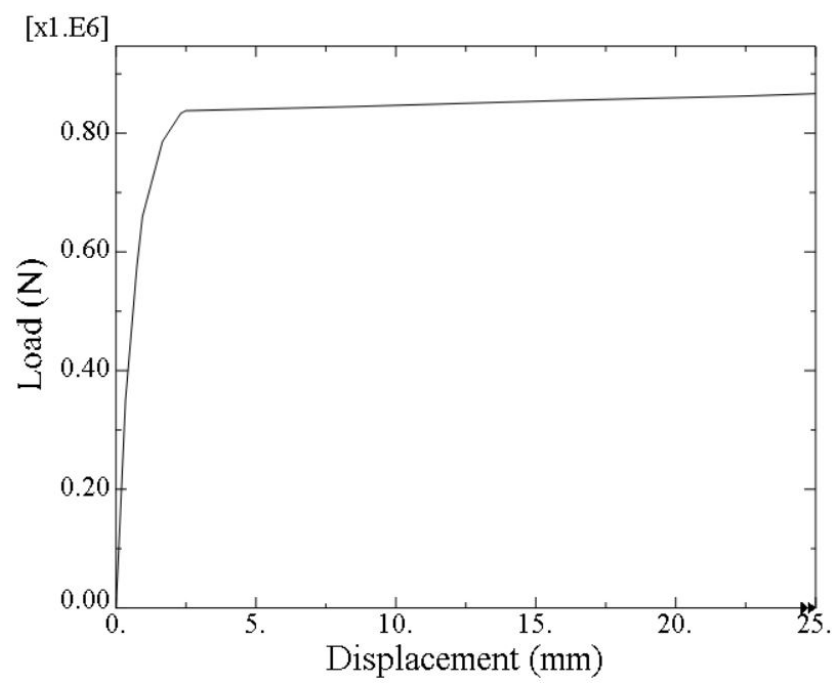

Figure 7. Load vs. displacement graph of $\mathrm{C} 1$ specimen in ABAQUS v6.14.

\section{Conclusion}

- Most of the specimens failed at the both ends due to local buckling.

- The effect of friction coefficient between concrete and steel tube had no significant effect on the axial load capacity of specimens.
Load vs. displacement graph obtained as field output for CC4-A-2 specimen on ABAQUS V6.14

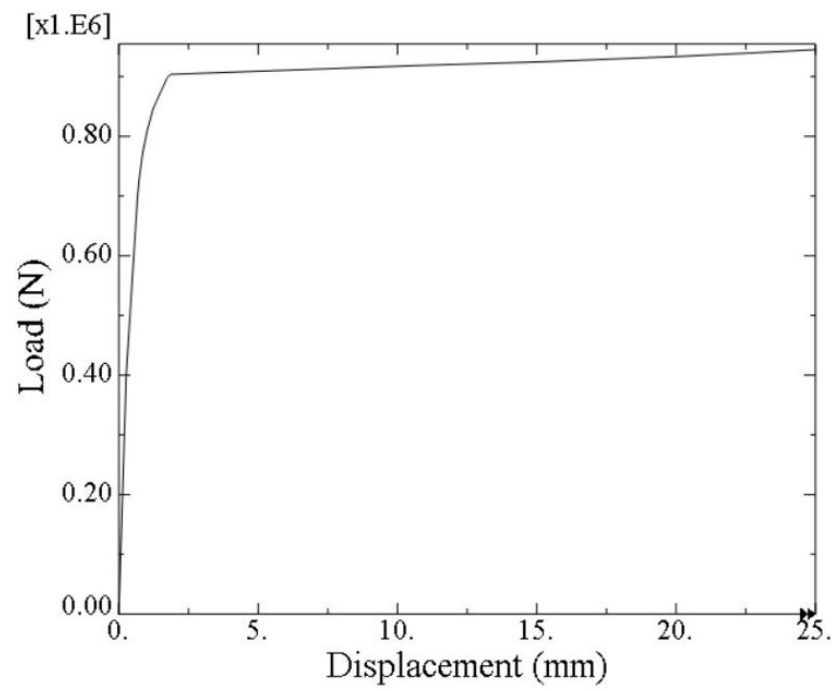

Figure 8. Load vs. displacement graph of CC4-A-2 specimen in ABAQUS v6.14.

Linear graph between axial load capacity and steel tube thickness for CC4-A-2 specimen obtained from axial load capacities simulated on ABAQUS V6.14

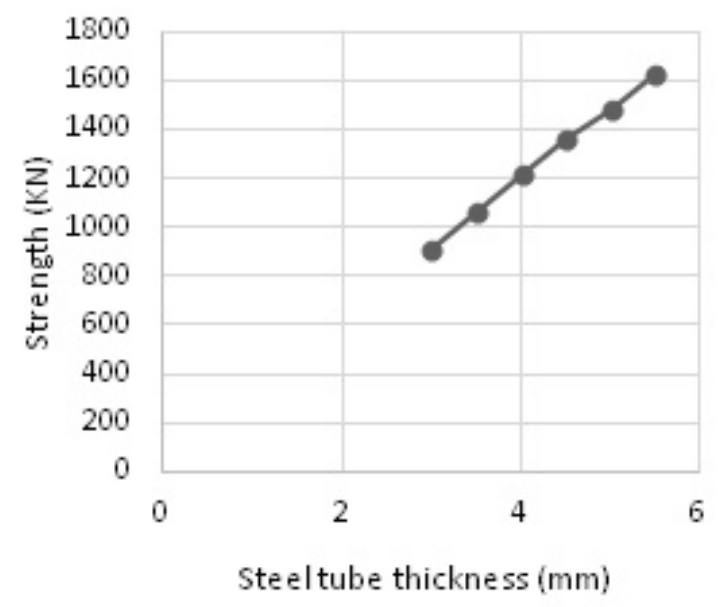

Figure 9. Strength vs. steel tube thickness for CC4-A-2 specimen.

- Local buckling was the most common failure in short CFST however in case of long columns buckling failure is also noticed.

- For interaction between concrete core and steel tube friction coefficient 0.05 , stiffness $500 \mathrm{KN} /$ $\mathrm{mm}^{3}$ and shear stress limit $0.6 \mathrm{MPa}$ gave best results for the validation of model. 
Different stresses in individual materials of same composite at same stage of loading

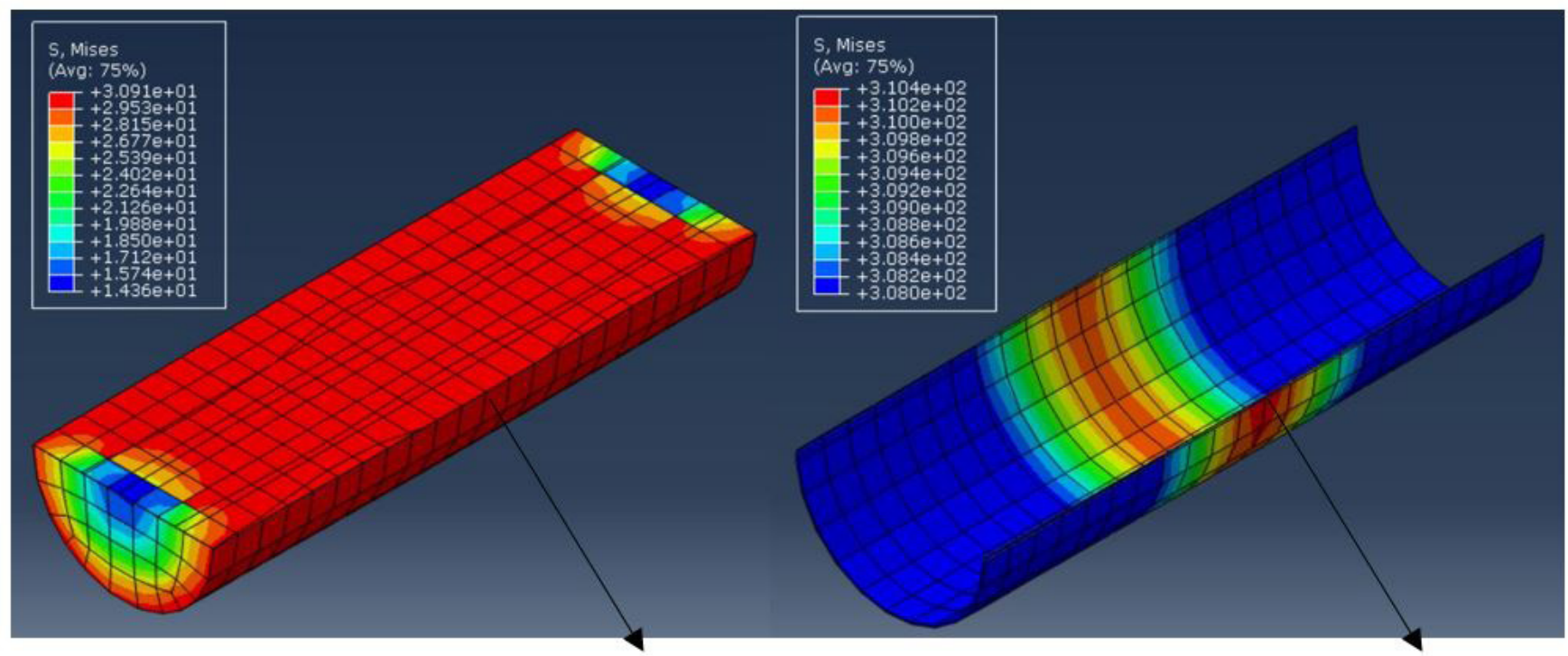

\section{Excessive lateral strain concentration}

Excessive confining pressure

Figure 10. Stresses in cut sections of concrete and steel respectively at 75\% stage of loading.

- It was also found that results from using plastic hardening property with stress and absolute plastic strain graph instead of Drucker Prager hardening gave more realistic results.

- Axial load capacity of specimen changes linearly with steel tube thickness keeping diameter of concrete core constant.

After studying the various increments of loading, it was found that concrete starts failing from the centre of longitudinal section. This failure then prolongs towards the both ends of longitudinal section. After failure in concrete it transfers load to the steel tube through friction and adhesion. This load transfer again starts from the centre of longitudinal section. At this moment concrete starts dilating from the centre and the stresses in steel tube gets concentrated at the centre of longitudinal section. After this concentrated force material starts failing towards the ends of section and leads to local buckling failure. Load vs. displacements graphs were also plotted in order to study the behavior of the composite during loading.

\section{Acknowledgement}

Firstly, I would like to show my gratitude to my mentor Mr. Aditya Tiwary who guided in right direction throughout my thesis. Secondly, I would like to thank my former mentor late Puneet Mittal who supported me in early stage of my research but couldn't see the fruit of it due to his early demise.

\section{References}

1. Dong CX, Kwan AKH, Ho JCM. Effects of external confinement on structural performance of Concrete Filled Steel Tubes. Journal of Constructional Steel Research. 2017 Dec; 132:72-82. https://doi.org/10.1016/j.jcsr.2016.12.024

2. Dong CX, Kwan AKH, Ho JCM. A constitutive model for predicting the lateral strain of confined concrete. Engineering Structures. 2015 Feb; 91:155-66. https:/doi. org/10.1016/j.engstruct.2015.02.014

3. Gardner NJ, Jacobson ER. Structural behavior of concrete-filled steel tubes. ACI Journal Proceedings. 1967; 64(7):404-12.

4. Ho JCM, Lam JYK, Kwan AKH. Effectiveness of adding confinement for ductility improvement of highstrength concrete columns. Engineering Structures. 2010 Dec; 32(3):714-25. https://doi.org/10.1016/j.engstruct.2009.11.017

5. Susantha KAS, Ge H, Usami T. Uniaxial stress-strain relationship of concrete confined by various shaped steel tubes. Engineering Structures. 2001; 23(10):1331-47. https://doi. org/10.1016/S0141-0296(01)00020-7 
6. Sakino K, Nakahara H, Morino S, Nishiyama I. Behavior of centrally loaded concrete-filled steel-tube short columns. Journal of Structural Engineering. 2004; 130(2):180-8. https://doi.org/10.1061/(ASCE)07339445(2004)130:2(180)

7. Fujimoto T, Mukai A, Nishiyama I, Sakino K. Behavior of eccentrically loaded concrete-filled steel tubular columns. Journal of Structural Engineering. 2004; 130(2):203-12. https://doi.org/10.1061/(ASCE)07339445(2004)130:2(203)

8. Pantazopoulou SJ, Mills RH. Micro-structural aspects of the mechanical response of plain concrete. ACI Materials Journal. 1995; 92(6):605-16.

9. Ouyang Y, Kwan AKH, Lo SH, Ho JCM. Finite element analysis of Concrete Filled Steel Tube (CFST) columns with circular sections under eccentric load. Engineering Structures. 2017; 148:387-98. https://doi.org/10.1016/j. engstruct.2017.06.064

10. Lai MH, Ho JCM. Effect of continuous spirals on uniaxial strength and ductility of CFST columns. Journal of Constructional Steel Research. 2015; 104:235-49. https:// doi.org/10.1016/j.jcsr.2014.10.007

11. Xue JQ, Briseghella B, Chen BC. Effects of debonding on circular CFST stub columns. Journal of Constructional Steel Research. 2012; 69(1):64-76. https://doi.org/10.1016/j. jcsr.2011.08.002

12. Tao Z, Song TY, Uy B, Han LH. Bond behavior in Concrete Filled Steel Tubes. Journal of Constructional Steel Research. 2016; 120:81-93. https://doi.org/10.1016/j.jcsr.2015.12.030

13. Hatzigeorgiou GD. Numerical model for the behavior and capacity of circular CFT columns Part I. Theory Engineering Structures. 2008; 30(6):1573-8. https://doi. org/10.1016/j.engstruct.2007.11.002

14. Liang QQ. High strength circular concrete-filled steel tubular slender beam columns. Part I: Numerical Analysis. Journal of Constructional Steel Research. 2011; 67(2):16471. https://doi.org/10.1016/j.jcsr.2010.08.006
15. Tailor A, Dalal SP, Desai AK. Comparative performance evaluation of steel column building and concrete filled tube column building under static and dynamic loading. Procedia Engineering. 2017; 173:1847-53. https://doi. org/10.1016/j.proeng.2016.12.233

16. Liang QQ, Fragomeni S. Nonlinear analysis of circular concrete-filled steel tubular short columns under axial loading. Journal of Constructional Steel Research. 2009; 65(2):2186-96. https://doi.org/10.1016/j.jcsr.2009.06.015

17. Hu HT, Huang CS, Wu MH, Wu YM. Nonlinear analysis of axially loaded concrete-filled tube columns with confinement effect. Journal of Structural Engineering. 2003; 129(10):1322-9. https://doi.org/10.1061/(ASCE)07339445(2003)129:10(1322)

18. Mander JB, Priestley MJN, Park R. Theoretical stress strain model for confined concrete. Journal of Structural Engineering.1998;114(8):1804-26. https://doi.org/10.1061/ (ASCE)0733-9445(1988)114:8(1804)

19. Richart FE, Anton B, Lenoi BR. A study of the failure of concrete under combined compressive stresses. University of Illinois at Urbana Champaign, College of Engineering. Engineering Experiment Station. 1928; 26(12):1-185.

20. Desayi P, Krishnan S. Equation for the stress-strain curve of concrete. ACI Journal Proceedings.1964; 61(3):1229-35.

21. Dai X, Lam D. Numerical modeling of the axial compressive behavior of short concrete-filled elliptical steel columns. Journal of Constructional Steel Research. 2010; 66(7):931-42. https://doi.org/10.1016/j.jcsr.2010.02.003

22. Schneider SP. Axially loaded concrete-filled steel tubes. Journal of Structural Engineering.1998; 124(10):1125-38. https://doi.org/10.1061/(ASCE)07339445(1998)124:10(1125)

23. Giakoumelis G, Lam D. Axial capacity of circular concrete-filled tube columns. Journal of Constructional Steel Research. 2004; 60(7):1049-68. https://doi.org/10.1016/j. jcsr.2003.10.001 